\title{
PLANEJAMENTO ESTRATÉGICO DE EMPRESA DO SETOR DE TELECOMUNICAÇÕES: UM ESTUDO DO USO PELOS GESTORES COMO APOIO AO PROCESSO DECISÓRIO
}

\author{
Carlos Eduardo de Oliveira, Universidade Federal de Uberlândia - UFU \\ carlos.oliveira@ufu.br \\ Ezequiel Lemes Nogueira Júnior, Universidade Federal de Uberlândia - UFU \\ ezequielnjunior@ hotmail.com \\ Érika Monteiro de Souza Alves Dias, Universidade Federal de Uberlândia - UFU \\ erikasavi@ufu.br \\ Renata Mendes de Oliveira, Universidade Federal de Uberlândia - UFU \\ renatamendes@ufu.br
}

\section{RESUMO}

O objetivo desse estudo foi verificar o uso do Planejamento Estratégico pelos líderes do canal de atendimento ao cliente de empresa do setor de telecomunicações. Esta pesquisa caracteriza-se como bibliográfica, descritiva, qualitativa e a coleta dos dados foram realizadas por meio de entrevista aplicada aos líderes de equipes, que atuam nos municípios de Belo Horizonte/MG, Franca/SP, Patos de Minas/MG, Ribeirão Preto/SP, Uberaba/MG e Uberlândia/MG, e que constantemente precisam tomar decisões que causarão impactos nos resultados da empresa. Como principais resultados observou-se que o Planejamento Estratégico existe formalmente na empresa, que planeja sua estratégia com base em ferramentas, como o Mapa Estratégico e o Balanced Scorecard. O Planejamento Estratégico é utilizado para que a organização possa garantir o alcance dos objetivos organizacionais, e serve de base para a elaboração do Planejamento Tático e Operacional, para que, posteriormente, ocorra a execução e o controle; observa-se a existência do distanciamento entre o que é planejado e o que de fato ocorre na empresa, pelo fato de que $57 \%$ dos líderes possuem conhecimento dos processos do Planejamento Estratégico e responsabilidade das áreas para garantir a continuidade dos processos, e os demais não conhecem totalmente as etapas deste tipo de planejamento, o que pode dificultar a execução das atividades de acordo com o que foi planejado. Dos critérios utilizados pelos líderes para tomar decisões, que envolvem variáveis internas e externas, qualitativas e quantitativas, o mais citado foi o desempenho na entrega do resultado. Com base na análise dos resultados os líderes decidem se é necessária adaptação ou continuidade da estratégia adotada.

Palavras-chave: Planejamento Empresarial, Planejamento Estratégico, Setor de Telecomunicações.

Data de recebimento: 14/04/2020

Data do aceite de publicação: 25/11/2020

Data da publicação: 30/12/2020 


\title{
STRATEGIC PLANNING OF A TELECOMMUNICATIONS SECTOR COMPANY: A STUDY OF USE BY MANAGERS AS SUPPORT FOR THE DECISION-MAKING PROCESS
}

\author{
Carlos Eduardo de Oliveira, Universidade Federal de Uberlândia - UFU \\ carlos.oliveira@ufu.br \\ Ezequiel Lemes Nogueira Júnior, Universidade Federal de Uberlândia - UFU \\ ezequielnjunior@hotmail.com \\ Érika Monteiro de Souza Alves Dias, Universidade Federal de Uberlândia - UFU \\ erikasavi@ufu.br \\ Renata Mendes de Oliveira, Universidade Federal de Uberlândia - UFU \\ renatamendes@ufu.br
}

\begin{abstract}
The objective of this study was to verify the use of Strategic Planning by the leaders of the customer service channel of a company in the telecommunications sector. This research is characterized as bibliographic, descriptive, qualitative and the data collection was carried out through interviews applied to team leaders, who work in the cities of Belo Horizonte/MG, Franca/SP, Patos de Minas/MG, Ribeirão Preto/SP, Uberaba/MG and Uberlândia/MG, and who constantly need to make decisions that will impact the company's results. As main results it was observed that Strategic Planning formally exists in the company, which plans its strategy based on tools, such as the Strategic Map and the Balanced Scorecard. The Strategic Planning is used so that the organization can guarantee the achievement of organizational objectives, and serves as a basis for the elaboration of the Tactical and Operational Planning, so that, subsequently, the execution and control occur; there is a gap between what is planned and what actually happens in the company, due to the fact that $57 \%$ of leaders have knowledge of the Strategic Planning processes and responsibility of the areas to guarantee the continuity of the processes, and the others they do not fully know the stages of this type of planning, which can make it difficult to carry out the activities according to what was planned. Of the criteria used by leaders to make decisions, which involve internal and external variables, qualitative and quantitative, the most cited was the performance in delivering the result. Based on the analysis of the results, the leaders decide if it is necessary to adapt or continue the adopted strategy.
\end{abstract}

Keywords: Business Planning, Strategic Planning, Telecommunications Sector.

\section{INTRODUÇÃO}

Diante da instabilidade econômica na qual o país vive atualmente, as empresas precisam planejar suas ações para manter sua sobrevivência e competitividade. Padoveze (2010, p. 24) descreve o Planejamento Estratégico como "um processo que prepara a empresa para o que está por vir”. Contudo, se a organização está preparada se torna um diferencial competitivo, consolidando o futuro da empresa. Para Chiavenato e Sapiro (2009, p. 25) "a estratégia sempre será uma escolha de um curso de ação para uma posição diferente no futuro que poderá oferecer ganhos e vantagens em relação à situação presente".

O planejamento possui três níveis distintos, com níveis hierárquicos diferentes, que segundo Chiavenato e Sapiro (2009) são: i) Planejamento Estratégico, que abrange 


\section{PLANEJAMENTO ESTRATÉGICO DE EMPRESA DO SETOR DE TELECOMUNICAÇÕES: UM ESTUDO DO USO PELOS GESTORES COMO APOIO AO PROCESSO DECISÓRIO}

toda a organização, sendo projetado em longo prazo; ii) Planejamento Tático, abrange cada departamento ou área específica da organização, sua projeção é a médio prazo; iii) Planejamento Operacional, abrange atividades específicas ou tarefas, sendo projetado a curto prazo para imediato.

Para Drucker (1984, p. 133), o "Planejamento Estratégico é o processo contínuo de, com o maior conhecimento possível do futuro considerado, tomar decisões atuais que envolvem riscos futuros aos resultados esperados". Portanto o Planejamento Estratégico pode ser utilizado como uma ferramenta para analisar os cenários futuros e assim tomar decisões que influenciarão nos resultados da organização.

Com o planejamento, execução e controle da empresa, os responsáveis devem constantemente tomar decisões, sejam específicas de um plano de ação operacional ou futurísticas, que envolvam o Planejamento Estratégico da empresa. A tomada de decisão pode ser a curto ou longo prazo e deve refletir a autoconfiança implícita dos responsáveis. A empresa está no envolto de variáveis controláveis e não controláveis, as decisões a serem tomadas são relativas apenas às variáveis controláveis, porém, os líderes precisam avaliar as variáveis não controláveis para minimizar riscos que o mercado pode apresentar no futuro (OLIVEIRA; CATANEO, 2009).

No Brasil, o setor de Telecomunicações é regulamentado pela Agência Nacional de Telecomunicações (ANATEL), responsável por adotar medidas necessárias para atendimento do interesse público e para o desenvolvimento das telecomunicações brasileiras. A Anatel possui o papel de fiscalizar, impor obrigações e aplicar sanções às operadoras atuantes no Brasil. Sua missão é promover o desenvolvimento das telecomunicações do país, de modo a dotá-lo de uma moderna e eficiente infraestrutura de telecomunicações, capaz de oferecer à sociedade serviços adequados, diversificados e a preços justos, em todo o território nacional. Segundo os relatórios consolidados divulgados pela Anatel, os serviços prestados pelas empresas de telecomunicações obtiveram aumento nos últimos anos, com destaque para a telefonia móvel que no fim de 2014 chegou a 280,7 milhões de acessos, atingindo uma densidade de 138 acessos para cada 100 habitantes no Brasil (ANATEL, 2015).

Segundo a Associação Brasileira de Telecomunicações (TELEBRASIL), no final do primeiro semestre de 2015, o setor de telecomunicações executou a prestação de serviços de telecomunicações para 373,6 milhões de assinantes, um aumento de 2,0\% comparado ao mesmo período de 2014. Os serviços prestados são: telefonia fixa e móvel, TV por assinatura, banda larga fixa e trunking (radiocomunicação). O setor possui uma grande participação na economia do país, produzindo, no primeiro semestre de 2015, uma receita operacional bruta de $\mathrm{R} \$ 118,6$ bilhões, com crescimento de 1,8\% em relação ao primeiro semestre de 2014, correspondente a 4,2\% do PIB Brasileiro (TELEBRASIL, 2015).

Nesse contexto, considera-se relevante realizar pesquisas que busquem apresentar resultados acerca do Planejamento Estratégico das empresas do setor de telecomunicações, e especificamente observar o uso do Planejamento Estratégico pelos líderes das empresas no processo decisório. Justifica-se a realização de estudos do setor de telecomunicações por possuir significativa importância para a economia brasileira, por apresentar evolução dos indicadores de desempenho nos últimos anos, e por ser um dos serviços indispensáveis na vida das pessoas e empresas. Acrescenta-se ainda que há crescente demanda de mercado para este setor, fazendo com que as empresas deste ramo de negócio busquem planejar o futuro. Diante do exposto, o presente estudo pretende responder à seguinte pergunta: como é utilizado o Planejamento Estratégico pelos líderes responsáveis pelo canal de atendimento aos clientes, de empresa do setor de telecomunicações, para a tomada de decisão? 


\section{PLANEJAMENTO ESTRATÉGICO DE EMPRESA DO SETOR DE TELECOMUNICAÇÕES: UM ESTUDO DO USO PELOS GESTORES COMO APOIO AO PROCESSO DECISÓRIO}

O objetivo deste estudo é verificar o uso do Planejamento Estratégico pelos líderes do canal de atendimento aos clientes de empresa do setor de telecomunicações. Portanto, pretende-se especificamente: a) verificar a existência formal do Planejamento Estratégico, b) identificar de que forma o Planejamento Estratégico é utilizado na gestão da empresa, c) analisar a existência do distanciamento entre o que é planejado e o que de fato ocorre na empresa, e d) identificar os critérios utilizados pelos líderes para a tomada de decisão.

O estudo será organizado em cinco seções. A primeira seção abrange a introdução; a segunda aborda a plataforma teórica, com todo embasamento utilizado para fundamentação da pesquisa; a terceira seção expõe a metodologia utilizada; a quarta trata da análise e a interpretação dos resultados, e, por fim, a quinta seção apresentará as considerações finais.

\section{PLATAFORMA TEÓRICA: PLANEJAMENTO, EXECUÇÃO E CONTROLE EMPRESARIAL}

Serão apresentados, nesta seção, alguns aspectos acerca do Planejamento, Execução e Controle, fundamentais para o processo de tomada de decisão nas empresas, com o intuito de clarificar o contexto no qual insere-se o objetivo deste estudo.

\subsection{Alguns aspectos do Planejamento Empresarial}

Observou-se na literatura pesquisada a importância da elaboração do Planejamento nas empresas e o acompanhamento de sua implementação. Esta subseção apresenta alguns aspectos do Planejamento Empresarial e as suas dimensões específicas, divididas em Planejamento Estratégico, Tático e Operacional.

Para Oliveira (2013), por meio do Planejamento Estratégico a empresa espera conhecer (i) os pontos fortes e como melhor utilizá-los, (ii) os pontos fracos, que são as desvantagens operacionais no ambiente empresarial, (iii) as oportunidades que podem favorecer sua ação estratégica, (iv) as ameaças externas, que se conhecidas em tempo hábil, podem ser evitadas.

Segundo Cavalcanti (2008), o Planejamento Estratégico refere-se à análise de possíveis alternativas a serem adotadas no longo prazo, para alcançar os principais objetivos das organizações, que estão condicionadas as metas estabelecidas.

O Quadro 1 apresenta sinteticamente alguns aspectos do Planejamento Empresarial.

Quadro 1 - Aspectos do Planejamento Empresarial

\begin{tabular}{|c|c|c|}
\hline Tema & Autor & Aspectos \\
\hline \multirow{4}{*}{ 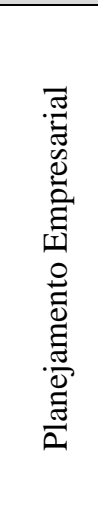 } & Oliveira (2013) & $\begin{array}{l}\text { O planejamento é um processo contínuo que envolve um conjunto complexo de } \\
\text { decisões inter-relacionadas que podem ser separadas de formas diferentes. }\end{array}$ \\
\hline & $\begin{array}{l}\text { Chiave } \\
\text { Sapiro }\end{array}$ & $\begin{array}{l}\text { O planejamento deve maximizar os resultados e minimizar as deficiências, } \\
\text { utilizando princípios de maior eficiência, eficácia e efetividade. Eles são os } \\
\text { principais critérios de avaliação da gestão. }\end{array}$ \\
\hline & $\begin{array}{c}\text { Oliveira e } \\
\text { Cataneo (2009) }\end{array}$ & $\begin{array}{l}\text { A deficiência no planejamento empresarial é um dos principais motivos para a } \\
\text { não continuidade das organizações. Os gestores precisam saber qual o futuro } \\
\text { pretendido para alcance da empresa, e diante de tanta competitividade, a missão e } \\
\text { os objetivos econômicos são fatores essências para manter a sobrevivência. A } \\
\text { tomada de decisões é facilitada quando existe um planejamento, pois a empresa } \\
\text { consegue mensurar e avaliar de forma quantitativa, e esse instrumento pode } \\
\text { abranger a empresa como um todo. }\end{array}$ \\
\hline & Oliveira e & A sobrevivência de uma organização está relacionada diretamente com o seu \\
\hline
\end{tabular}


PLANEJAMENTO ESTRATÉGICO DE EMPRESA DO SETOR DE TELECOMUNICAÇÕES: UM ESTUDO DO USO PELOS GESTORES COMO APOIO AO PROCESSO DECISÓRIO

\begin{tabular}{|c|c|l|}
\hline Cataneo (2009) & \begin{tabular}{l} 
planejamento. As decisões tomadas no presente irão refletir no futuro. \\
\cline { 2 - 4 }
\end{tabular} & $\begin{array}{l}\text { Em um mundo de negócios onde as mudanças são constantes, o planejamento é } \\
\text { uma estratégia para aumentar as chances de sucesso, porém não garante o } \\
\text { sucesso, pois sua eficácia depende das premissas nele incluídas. }\end{array}$ \\
\cline { 2 - 4 } & Pereira (2010) & $\begin{array}{l}\text { Planejamento pode ser o processo formalizado para gerar resultados a partir de } \\
\text { um sistema integrado de decisões. }\end{array}$ \\
\hline Pereira (2010) & $\begin{array}{l}\text { As empresas precisam criar planos que não sejam rígidos demais, a ponto de } \\
\text { engessar os processos, e os líderes precisam garantir que os planejamentos sejam } \\
\text { contínuos. }\end{array}$ \\
\hline
\end{tabular}

Fonte: Elaborado pelos autores.

Portanto, o planejamento empresarial envolve uma complexidade de processos decisórios, os quais os gestores precisam ter uma visão de forma separada para cada acontecimento, que no fim inter-relacionam-se, e deverão gerar os resultados esperados. Adiciona-se ainda que o planejamento busca minimizar os erros dos tomadores de decisões, evitando improvisos que impactam o resultado, e procura dar foco nas melhores escolhas para obtenção dos resultados desejados. Devido à sua relevância e complexidade, o planejamento empresarial pode ser separado e desenvolvido considerando-se as seguintes dimensões: estratégico, tático e operacional.

Planejamento Estratégico consiste em analisar de forma sistemática os pontos fortes e fracos da organização, e das oportunidades e ameaças do ambiente externo, com o objetivo de formular estratégias com intuito de aumentar a competividade e seu grau de resolutividade (PEREIRA, 2010).

$\mathrm{Na}$ elaboração do Planejamento Estratégico pelos gestores da empresa, torna-se relevante a evidenciação (i) da visão e missão, (ii) suas metas e objetivos, e (iii) seus objetivos gerais e específicos (OLIVEIRA, 2020).

A Visão serve para transmitir aos colaboradores a intenção da empresa, direcionando de que forma serão alcançados os objetivos definidos pela direção, o caminho a ser seguido, e assim fazer com que todos os colaboradores se sintam parte da execução, mantendo um ambiente motivado e organizado, a empresa precisa definir de forma clara para todos e manter um alinhamento entre a visão e o que de fato é realizado pelos colaboradores (OLIVEIRA; CATANEO, 2009).

Segundo Hitt, Ireland e Hoskisson (2008, p.18) "A missão da empresa é mais concreta do que a visão. Porém, assim como a visão deve definir a individualidade de uma empresa, deve ser inspiradora e relevante para todos os stakeholders.". Na concepção de Oliveira e Cataneo (2009, p. 5), "a missão da empresa deve estabelecer a direção dos esforços e o compromisso com os envolvidos, sendo o instrumento de direção estratégica e sua execução".

Segundo Padoveze e Taranto (2009), no processo de elaboração e execução do Planejamento Estratégico, o modelo SWOT de análise do ambiente é uma ferramenta que possui uma aceitação com bom desempenho. Oliveira (2020) aponta que a análise SWOT realiza a avaliação do ambiente interno, indicando seus pontos fortes e fracos, bem como do ambiente externo, apontando as oportunidades de negócio e as ameaças que poderão comprometer o atingimento da meta definida pela empresa.

Para Padoveze (2010), a análise SWOT identifica quais os pontos importantes no futuro e como estarão os negócios da empresa mediante a competição e as expectativas do mercado, revela áreas a serem trabalhadas, que podem até mudar os objetivos da empresa, e aponta problemas que poderão surgir.

A Figura 1 apresenta orientações acerca da análise SWOT, onde estão inseridos os ambientes externos e internos, as oportunidades e ameaças, e os pontos fortes e fracos.

Figura 1 - Análise SWOT 
PLANEJAMENTO ESTRATÉGICO DE EMPRESA DO SETOR DE TELECOMUNICAÇÕES: UM ESTUDO DO USO PELOS GESTORES COMO APOIO AO PROCESSO DECISÓRIO

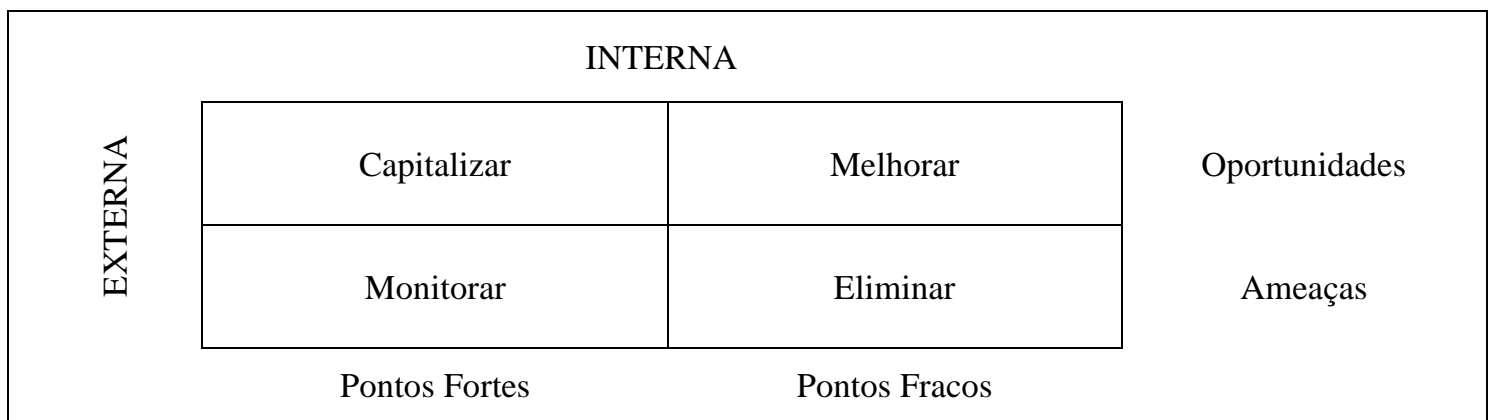

Fonte: Adaptado de Padoveze e Taranto (2009).

Uma da ferramenta que pode ser utilizada para mensurar os resultados do Planejamento Estratégico é o Balanced Scorecard (BSC). Segundo Kaplan e Norton (1997), o BSC traduz a missão e a estratégia das empresas num conjunto que abrangente de medidas de desempenho que serve de base para um sistema de medição e gestão estratégica.

O BSC sugere a criação de mapas estratégicos, que possuem a função de transformar os ativos intangíveis em resultados tangíveis para os clientes, e por consequência, a empresa obtém resultados financeiros, ao distribuir em partes que formam uma cadeia lógica de causa e efeito, onde a execução estratégica, baseada nos vetores, levará aos resultados esperados (SILVA; SANTOS; SANTOS, 2006). Ele avalia os vetores que influenciam o crescimento futuro da organização, atendendo aos interesses financeiros, a visão do cliente sobre a empresa, a perspectiva interna, para saber quais processos precisam ser melhorados e mais eficientes, e avalia a inovação e aprendizagem organizacional, para evidenciar o que pode também ser melhorado e criar valor agregado (KAPLAN; NORTON, 1997).

Para medir o ativo tangível das empresas, alguns indicadores são utilizados, como: balanço contábil, demonstrativos financeiros, retorno sobre investimento, produtividade e outros. Porém, esses tipos de medidas podem ser avaliados apenas de forma quantitativa. Para Chiavenato (2004), o BSC envolve o ativo intangível, trazendo o equilíbrio organizacional em quatro perspectivas, que conforme o mapa estratégico, atingem o principal objetivo da empresa, que é o lucro (CHIAVENATO, 2004). A Figura 2, apresenta as quatro perspectivas no mapa estratégico.

Figura 2 - Mapa estratégico 


\section{PLANEJAMENTO ESTRATÉGICO DE EMPRESA DO SETOR DE TELECOMUNICAÇÕES: UM ESTUDO DO USO PELOS GESTORES COMO APOIO AO PROCESSO DECISÓRIO}

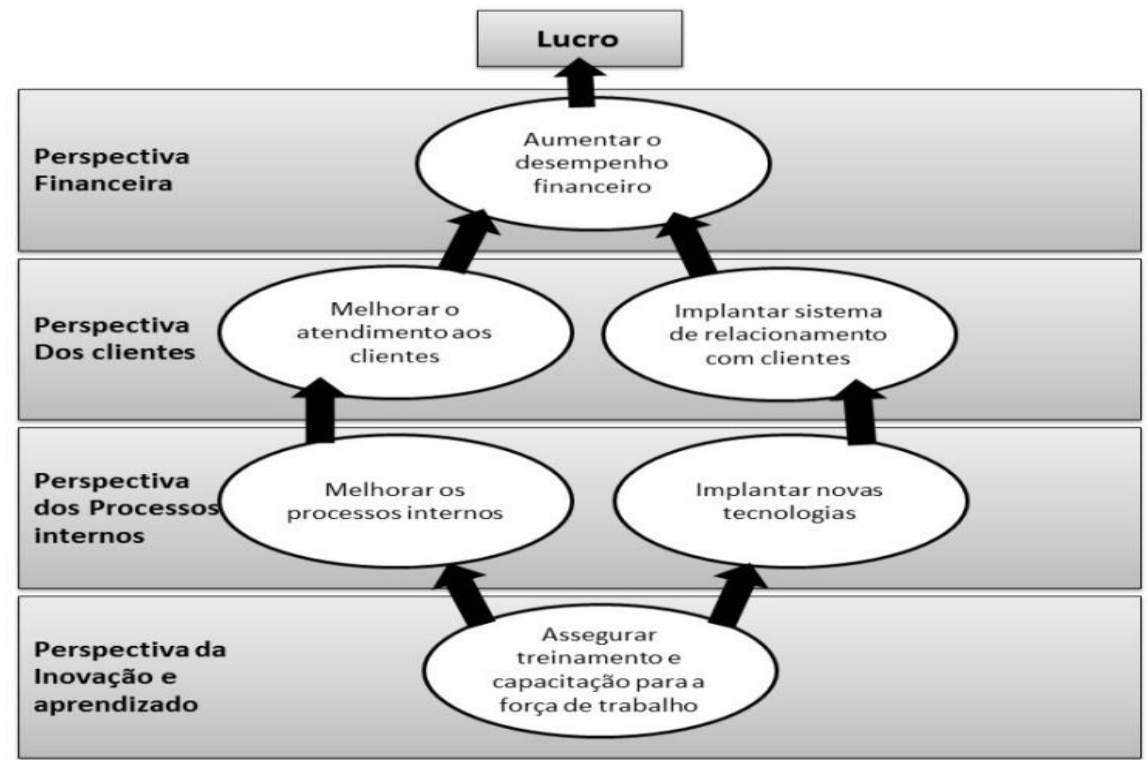

Fonte: Adaptado de Chiavenato (2004).

Até este momento foram abordados alguns aspectos do Planejamento Estratégico. Dada a relevância acerca do detalhamento do planejamento, no Quadro 2 serão apresentados alguns aspectos do Planejamento Tático e Operacional.

Quadro 2 - Aspectos do Planejamento Tático e Operacional

\begin{tabular}{|c|c|c|}
\hline Tema & Autor & Aspectos \\
\hline \multirow{4}{*}{ 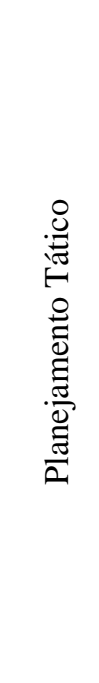 } & $\begin{array}{l}\text { Oliveira } \\
\text { (2013) }\end{array}$ & $\begin{array}{l}\text { O planejamento tático tem a finalidade de otimizar apenas uma área de resultado, } \\
\text { sendo que seu foco não é a empresa como um todo. O Planejamento Estratégico } \\
\text { define os objetivos, políticas e estratégias, enquanto o tático trabalha com as } \\
\text { decomposições dessas definições. }\end{array}$ \\
\hline & $\begin{array}{c}\text { Chiavenato } \\
\text { (2007) }\end{array}$ & $\begin{array}{l}\text { O planejamento tático é o conjunto de tomada deliberada e sistemática de decisão } \\
\text { sobre empreendimentos mais limitados, prazos mais curtos, áreas menos amplas e } \\
\text { níveis mais baixos da hierarquia da organização. }\end{array}$ \\
\hline & $\begin{array}{l}\text { Oliveira e } \\
\text { Cataneo } \\
(2009)\end{array}$ & $\begin{array}{l}\text { Nessa etapa não são realizadas as operações do dia-a-dia, pois essa é a função do } \\
\text { planejamento operacional, com a definição estratégica da empresa, o } \\
\text { Planejamento Tático começa a tomar formato, escolhendo alternativas viáveis } \\
\text { economicamente. }\end{array}$ \\
\hline & $\begin{array}{l}\text { Hoji e } \\
\text { Silva } \\
(2010)\end{array}$ & $\begin{array}{l}\text { O Planejamento Tático é a derivação do Planejamento Estratégico para otimizar } \\
\text { uma área específica, onde a alta administração realiza as decisões estratégicas e } \\
\text { cabe a cada responsável por área fazer com que se torne realidade o que foi } \\
\text { planejado anteriormente. Nessa etapa, o alcance temporal é mais curto que o } \\
\text { estratégico e no nível intermediário, envolvendo áreas que fazem parte dos planos } \\
\text { definidos para concretizar as decisões tomadas no nível estratégico. }\end{array}$ \\
\hline \multirow{3}{*}{ 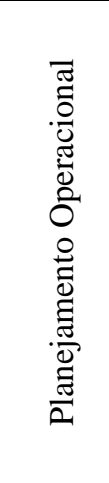 } & $\begin{array}{l}\text { Oliveira } \\
(2013)\end{array}$ & $\begin{array}{l}\text { Planejamento Operacional é a formalização, principalmente através de } \\
\text { documentos escritos, das metodologias de desenvolvimento e implementação de } \\
\text { resultados específicos a serem alcançados pelas áreas funcionais da empresa. }\end{array}$ \\
\hline & $\begin{array}{l}\text { Oliveira e } \\
\text { Cataneo } \\
(2009)\end{array}$ & $\begin{array}{l}\text { O Planejamento Estratégico cria os parâmetros para que o nível tático e } \\
\text { operacional desenvolva o Planejamento Operacional. Nessa fase, a execução das } \\
\text { atividades deve acontecer, sendo assim precisa ser bem definido quem serão os } \\
\text { responsáveis pelas funções operacionais de cada departamento, e o que cada } \\
\text { colaborador que participa desse departamento operacional deve fazer. }\end{array}$ \\
\hline & $\begin{array}{l}\text { Hoji e } \\
\text { Silva } \\
(2010)\end{array}$ & $\begin{array}{l}\text { O Planejamento Operacional é distribuído em ações realizadas por áreas e em } \\
\text { tempos diferentes, sendo que nessa etapa está em um nível onde a execução das } \\
\text { ações acontece com planos específicos para cada departamento, mas que, em sua } \\
\text { totalidade, garantem uma maximização dos recursos da empresa. }\end{array}$ \\
\hline
\end{tabular}

Fonte: Elaborado pelos autores. 


\section{PLANEJAMENTO ESTRATÉGICO DE EMPRESA DO SETOR DE TELECOMUNICAÇÕES: UM ESTUDO DO USO PELOS GESTORES COMO APOIO AO PROCESSO DECISÓRIO}

Considerando os aspectos abordados no Quadro 2, pode-se destacar que o Planejamento Tático é desenvolvido pelo nível hierárquico intermediário, sendo interligado com o Planejamento Estratégico, e o seu papel é o de otimizar uma área específica. Após a sua definição, é elaborado o Planejamento Operacional, que possui um nível maior de detalhamento de informações, pois este é realizado pelo nível hierárquico que executa as tarefas. Nesta etapa, consegue-se chegar ao estágio da execução, onde são desenvolvidas as atividades dia-a-dia da organização, e é projetado para o curto prazo, e deve possuir basicamente os planos de ação ou planos operacionais.

\subsection{Execução}

A elaboração e implementação do planejamento estratégico servem de base para execução. O planejamento pode apresentar falhas no momento da execução, portanto a execução do planejamento é uma das principais etapas, e por melhor que seja formulado o planejamento, se a execução da estratégia não for cuidadosamente implementada, não será bem-sucedida (CHIAVENATO; SAPIRO, 2009).

Para Oliveira e Cataneo (2009), a execução é o momento de "fazer acontecer", quando implementado o planejamento, é o momento em que aparecem as dificuldades. $\mathrm{Na}$ elaboração do planejamento cada departamento colabora, e os funcionários precisam saber todos os detalhes da sua execução. Para que isso aconteça é necessária uma clareza na delegação de atividades dos líderes. Os planos de execução devem estar em consonância com o que foi planejado, para assim contribuir efetivamente com o alcance dos objetivos organizacionais.

A execução da estratégia é um momento que exige sinergia de todas as áreas da empresa, desde o presidente até a base da estrutura organizacional. Esse processo requer muito engajamento para que as tarefas cotidianas sejam integradas por toda organização. $\mathrm{O}$ alinhamento dos objetivos organizacionais precisa ser claro e motivar a todos para que haja um compromisso de entrega em cada parte da empresa. A execução é a etapa mais demorada, com elevado grau de dificuldade e complexidade. $\mathrm{O}$ planejamento estratégico não pode ser apenas elaborado, ele precisa ser efetivamente executado (CHIAVENATO; SAPIRO, 2009).

\subsection{Controle}

Ao serem estabelecidas as metas, desafios e objetivos, a empresa precisa saber se as ações realizadas estão resultando de forma positiva, ou se é preciso corrigir ou reforçar as ações para alcançar os objetivos. Para isso, o controle se faz necessário, sendo uma função do processo administrativo utilizada para avaliar e medir o desempenho, com finalidade de realimentar os tomadores de decisões. O controle é uma etapa importante do Planejamento Estratégico, pois trata-se da retroalimentação, onde as informações são relevantes para a continuidade das ações ou correções, para efetivo alcance dos objetivos (OLIVEIRA, 2013).

Para Figueiredo e Caggiano (2004), o controle dá um feedback aos gestores acerca dos resultados obtidos comparados aos objetivos planejados. Sem o controle, o Planejamento Estratégico não consegue ser avaliado. Para avaliar sua eficiência, é necessário comparar os resultados com o que foi definido com objetivo. Nessa etapa o tomador de decisão terá um grande suporte, pois, ao avaliar todos os feedbacks, ele poderá executar as melhores ações para cada período vivido pela organização, no curto ou longo prazo. 


\section{PLANEJAMENTO ESTRATÉGICO DE EMPRESA DO SETOR DE TELECOMUNICAÇÕES: UM ESTUDO DO USO PELOS GESTORES COMO APOIO AO PROCESSO DECISÓRIO}

Basicamente, o controle envolve (i) obter dados do planejamento da empresa para determinado período, (ii) obter dados das atividades executadas, (iii) confrontar os dados do planejamento com os executados, e (iv) apresentar os resultados aos gestores, destacando as variações ocorridas entre o planejado e o executado (OLIVEIRA, 2020). A definição do processo administrativo da função controle pode ser visto na Figura 3.

Figura 3 - Conceituação geral da função controle e avaliação

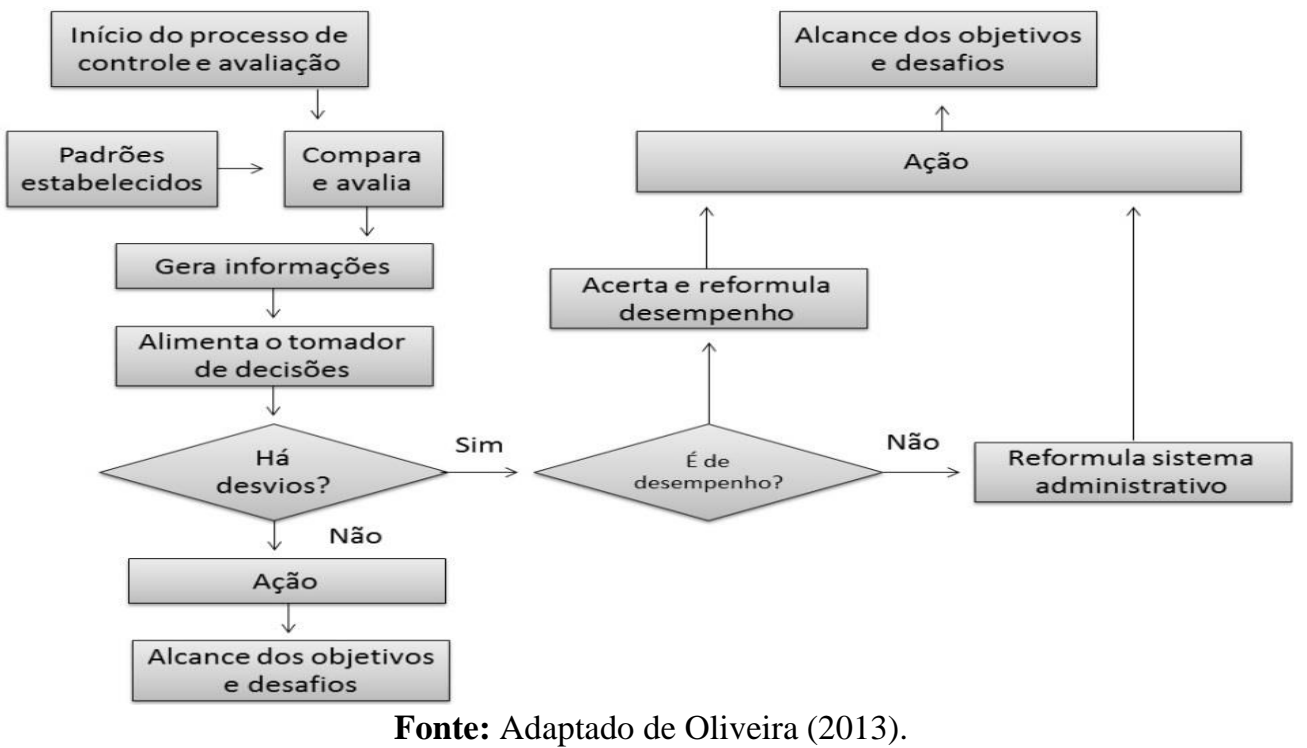

Com o planejamento, execução e controle da empresa, os responsáveis devem constantemente tomar decisões, sejam específicas de um plano de ação operacional ou futurísticas, que envolvam o estratégico da empresa. A tomada de decisão pode ser a curto ou longo prazo e deve refletir a autoconfiança implícita dos responsáveis. A empresa está no envolto de variáveis controláveis e não controláveis, e assim, as decisões a serem tomadas são relativas a apenas variáveis controláveis, porém os líderes precisam avaliar as variáveis não controláveis para minimizar riscos que o mercado pode apresentar no futuro, visto que se elas forem identificadas, a empresa pode criar planos antecipativos para combater essas variáveis (OLIVEIRA; CATANEO, 2009). Considerando-se a relevância do tema, a subseção a seguir apresenta alguns estudos relacionados com a presente pesquisa.

\subsection{Estudos anteriores}

Mankins e Steele (2006) defenderam em sua pesquisa que as empresas precisam parar de criar um planejamento e começar a tomar decisões. Os resultados do estudo sugerem que o fracasso do planejamento estratégico é devido a dois fatores: (i) ao tempo, que geralmente é desenvolvido em um processo anual de planejamento, e (ii) frequentemente existe a centralização das decisões em pessoas específicas nas unidades de negócio, impedindo que algumas decisões sejam tomadas em maior quantidade, melhor qualidade e com mais agilidade.

Bataglia e $\mathrm{Yu}$ (2008) analisaram como as empresas sincronizam a tomada de decisão estratégica com o planejamento estratégico formal. $\mathrm{O}$ estudo foi realizado junto a quatro agroindústrias do Estado de São Paulo. A análise revelou que o processo de autorização é centralizado e formal; as decisões previstas no plano orçamentário são reavaliadas e autorizadas pela alta administração imediatamente antes da primeira 


\section{PLANEJAMENTO ESTRATÉGICO DE EMPRESA DO SETOR DE TELECOMUNICAÇÕES: UM ESTUDO DO USO PELOS GESTORES COMO APOIO AO PROCESSO DECISÓRIO}

alocação de capital e quando as novas decisões não estão programadas no plano orçamentário são autorizadas via realocação ou suplementação de verbas.

Ribeiro, Garcia e Casas (2010) realizaram uma pesquisa referente à estratégia e vantagem competitiva no mercado brasileiro de telecomunicações no período pósprivatização (1999 a 2007). O resultado da pesquisa sugere que as principais razões para obterem um desempenho econômico superior foram estratégias de redução de custos e a posse de recursos intangíveis, e as principais razões para o pior desempenho foi a utilização de estratégias equivocadas relativas ao padrão tecnológico do setor e o investimento em índices de rentabilidade questionável, como a participação de mercado.

Ferreira e Diehl (2012) investigaram a relação entre o orçamento e o Planejamento Estratégico das organizações. Foi realizado um ensaio teórico por meio de reflexões e análises das teorias divulgadas. A análise da abordagem dos diferentes autores mostraram a existência do alinhamento entre o planejamento estratégico e o orçamento, e há diferentes visões acerca da questão da sua concepção, sobre em qual nível hierárquico ocorre tal relação.

Duarte e Azeredo (2013) analisaram como alinhar o orçamento empresarial ao Planejamento Estratégico de empresa prestadora de serviços. A pesquisa exploratória e qualitativa sugere a existência de um fluxo de trabalho voltado às interações entre os processos de orçamento e Planejamento Estratégico e a integração com a análise de produtos, objetivando o alcance dos resultados desejados pela empresa.

\section{PROCEDIMENTOS METODOLÓGICOS}

Realizou-se inicialmente a pesquisa bibliográfica, com a finalidade de obter alguns aspectos teóricos acerca do tema, para a construção da fundamentação teórica do estudo. Para Gil (1999), a pesquisa bibliográfica pode ser constituída, entre outros, pelos livros e artigos científicos.

Esta pesquisa possui caráter descritivo, que segundo Gil (1999), é aquela que utiliza uma população ou fenômeno para levantar as características dos mesmos, ou estabelece relações através de variáveis. A pesquisa também possui caráter exploratório, que, para Severino (2007), busca levantar informações sobre determinado objeto, delimitando assim um campo de trabalho, mapeando as condições de manifestação desse objeto.

A pesquisa foi realizada em uma empresa do setor de telecomunicações, e o seu nome não foi divulgado a fim de manter a confidencialidade do estudo. Trata-se de uma empresa com atuação em 192 municípios, que realiza atendimento aos clientes residenciais e corporativos. Os líderes da empresa fazem parte do segmento responsável pelo atendimento ao cliente corporativo/empresarial de Micro e Pequenas Empresas (MPE).

Foram utilizados dados primários, coletados junto ao seguintes líderes: Coordenador, Supervisores, Gestores de Vendas e Analista de Negócios do canal de atendimento ao cliente. Os líderes foram selecionados por amostragem não probabilística e por acessibilidade. A coleta dos dados foi realizada por meio de entrevista estruturada, que teve como objetivo obter dados sobre o conhecimento dos líderes acerca do Planejamento Estratégico, sua forma de utilização, as dificuldades encontradas na execução do planejamento e a utilização do Planejamento Estratégico na tomada de decisão.

Os dados coletados foram tratados de forma qualitativa, onde foi possível realizar a análise do conteúdo das informações disponibilizadas por meio da coleta de dados, e 


\section{PLANEJAMENTO ESTRATÉGICO DE EMPRESA DO SETOR DE TELECOMUNICAC̄̃̃ES: UM ESTUDO DO USO PELOS GESTORES COMO APOIO AO PROCESSO DECISÓRIO}

os resultados serão apresentados no formato de figuras, quadros e também de forma descritiva.

\section{ANÁLISE E INTERPRETAÇÃO DOS RESULTADOS}

Para iniciar a pesquisa foi analisada a formalidade do Planejamento Estratégico da empresa, por meio de documentos recebidos via e-mail de um dos líderes da empresa, que exerce o cargo de Supervisão no município de Ituiutaba/MG, o qual não participou das entrevistas. A coleta dos dados ocorreu no ano de 2015.

Com base nesses documentos, foi identificada a existência de um processo formal e bem definido de elaboração do Planejamento Estratégico. A empresa concluiu a implementação do Planejamento Estratégico, que utiliza direcionadores estratégicos

A empresa possui um programa de Planejamento Estratégico que obteve a formulação da estratégia corporativa e definição dos direcionadores estratégicos que foram concluídos em 2013. As estratégias são desdobradas em objetivos e projetos para algumas áreas da empresa, para que essas áreas pudessem contribuir na execução do plano.

A empresa possui um portal eletrônico interno, para que os funcionários possam acompanhar todo o processo do Planejamento Estratégico, desde a implantação dos planos até o acompanhamento dos resultados; toda semana a empresa faz uma reunião em modelo de talk show, onde todos os colaboradores da organização, de qualquer nível hierárquico, podem participar. Esta reunião acontece em seu centro administrativo, e é transmitida por videoconferência para todas as cidades onde possuem escritórios. Nessas reuniões os responsáveis pelos planos, que são desdobrados pelo Planejamento Estratégico, apresentam o status dos planos e realizam o alinhamento das expectativas. Nesse momento, todos os funcionários podem fazer perguntas e contribuir com sugestões, interagindo com a execução e controle dos planos estratégicos.

Diante da proposta de estudo, na análise da utilização do Planejamento Estratégico pelos líderes da empresa, alguns estágios são definidos pela organização com intenção de orientar o líder no processo do Planejamento Estratégico, que liga a formulação e o planejamento da estratégia com a execução e controle. Essas etapas podem ser vislumbradas da Figura 4.

Figura 4 - Etapas do Planejamento Estratégico da empresa pesquisada 


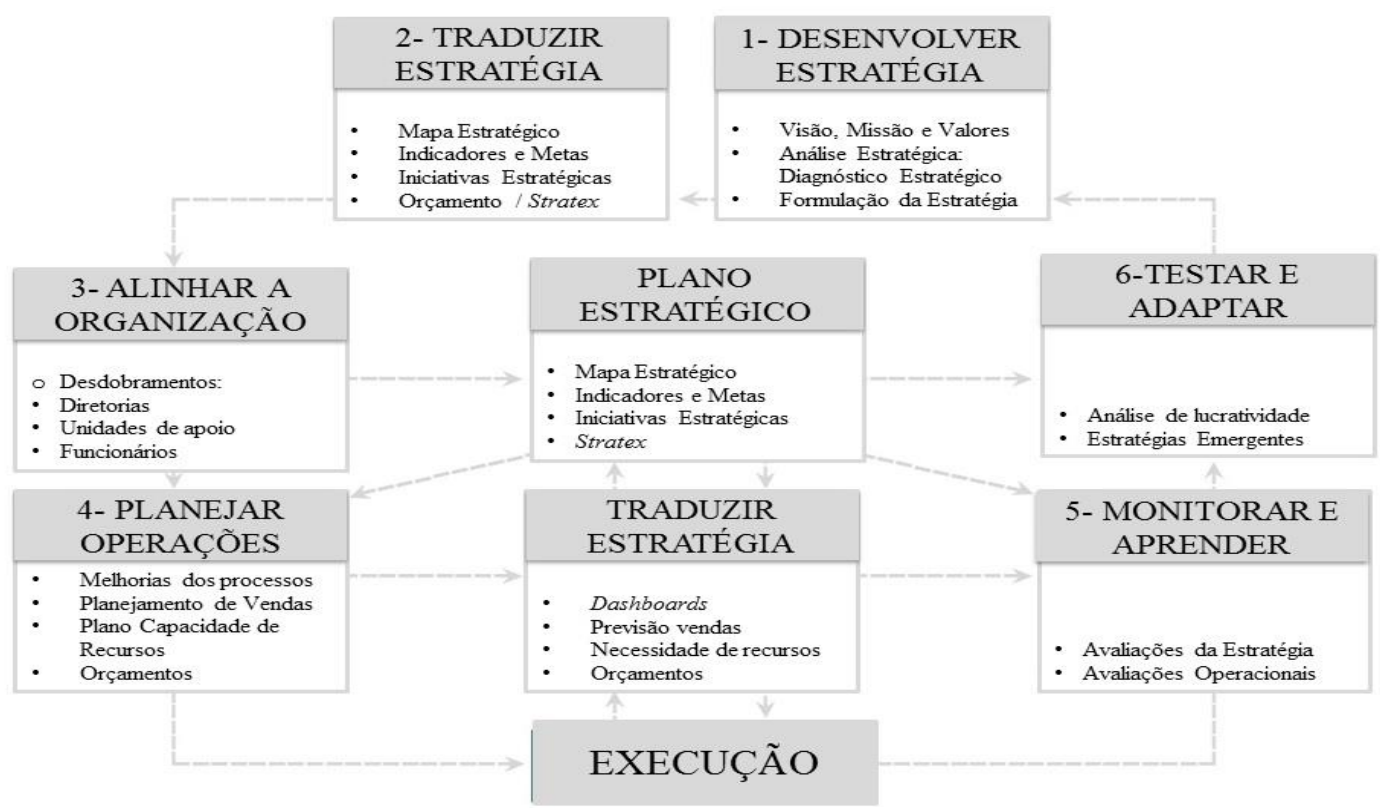

Fonte: Dados da pesquisa.

De modo consolidado, a utilização se faz em estágios. No $1^{\circ}$ estágio acontece o desenvolvimento da estratégia por parte do líder; no $2^{\circ}$ estágio, a organização planeja a estratégia com base em ferramentas como Mapa Estratégico e Balanced Scorecard (BSC); no $3^{\circ}$ estágio, depois da elaboração do Mapa Estratégico e do BSC, os gestores alinham a organização com a estratégia, por meio de desdobramentos com mapas estratégicos e BSCs interligados para as unidades organizacionais, e é realizado o alinhamento do Planejamento Estratégico com o Planejamento Tático de cada área.

No $4^{\circ}$ estágio, o líder planeja a execução, desenvolvendo assim o Planejamento Operacional; no $5^{\circ}$ estágio, na medida em que se executa a estratégia e os planos operacionais, a empresa monitora e aprende sobre problemas, barreiras e desafios. Esse processo integra informações sobre operações e estratégias, por meio de um sistema de reuniões de análise de gestão; no $6^{\circ}$ estágio, os líderes usam dados operacionais internos e novas informações sobre o ambiente externo, para testar e adaptar a hipótese estratégica, lançando outros procedimentos em torno do sistema integrado de planejamento estratégico.

Para iniciar todo o processo do Planejamento Estratégico, a empresa definiu sua missão, visão de negócio e proposta de valor, no qual direciona os funcionários para elaboração de um posicionamento estratégico, que possui três pilares, com foco em Defesa, Expansão e Eficiência da organização, no qual irá sustentar todo o Planejamento Estratégico da empresa, na apresentação dos planos, todos estão em consonância com os pilares. Após essa definição, a estratégia é traduzida em uma arquitetura lógica, que contempla e demonstra, de forma didática, a estratégia da organização, em quatro grandes dimensões (acionistas, clientes, processos de negócios e competências), e suas relações.

O BSC é utilizado como o instrumento de mensuração de resultados do Planejamento Estratégico, no qual é realizado um mapa estratégico, para explicar os temas selecionados pela organização como os mais prioritários, mostrando o caminho que a organização deve atuar para atingir a visão. A partir dele são construídos painéis de contribuição de todas as áreas da empresa. 


\section{PLANEJAMENTO ESTRATÉGICO DE EMPRESA DO SETOR DE TELECOMUNICAÇÕES: UM ESTUDO DO USO PELOS GESTORES COMO APOIO AO PROCESSO DECISÓRIO}

A pesquisa foi realizada com sete líderes da empresa, sendo que todos fazem a gestão de equipes; devido ao cargo, é necessária a utilização do Planejamento Estratégico e precisam tomar decisões constantemente, que causarão impactos nos resultados da empresa. A Figura 5 apresenta os níveis hierárquicos dos participantes da pesquisa, eles possuem um asterisco $\left(^{*}\right)$ para serem identificados.

Figura 5 - Nível hierárquico dos entrevistados

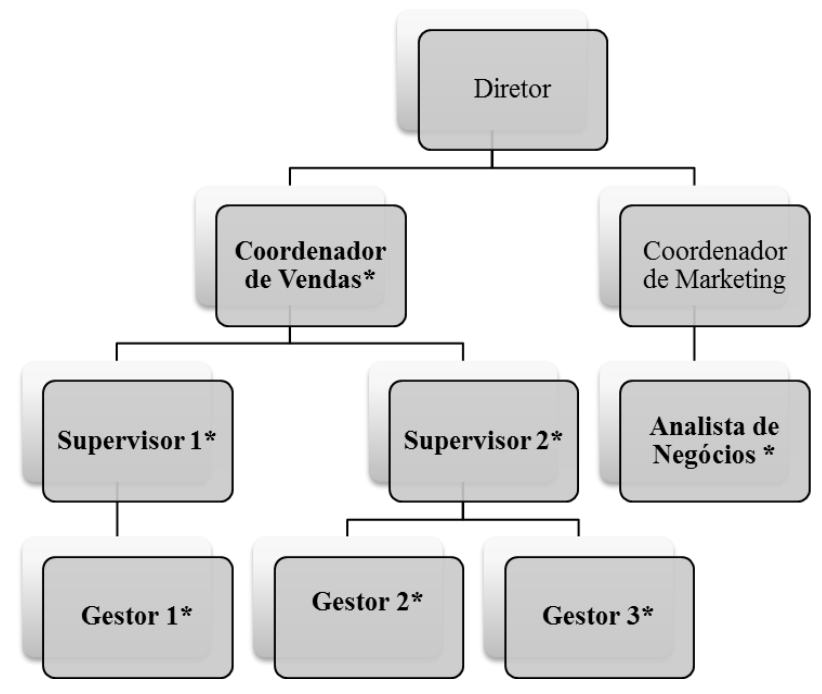

Fonte: Elaborado pelos autores.

Um dos entrevistados ocupa o cargo de Coordenador de Vendas, seu nível hierárquico é o segundo maior do segmento, respondendo diretamente para o Diretor; dois entrevistados são Supervisores, que cuidam de todos os gestores de seus respectivos estados: Minas Gerais e São Paulo; três dos entrevistados são gestores responsáveis por liderar equipes de vendedores que estão nas cidades de Franca/SP, Patos de Minas/MG e Uberaba/MG; um entrevistado está no cargo de Analista de Negócios, responsável por gerenciamento de projetos que são desenvolvidos dentro dos pilares estratégicos, utilizando os planejamentos para gerenciar projetos junto a uma equipe, seu nível hierárquico responde diretamente para o Coordenador de Marketing da empresa.

O Quadro 3 apresenta alguns aspectos do Planejamento Estratégico, Execução e Controle, obtidos com as entrevistas, que foram realizadas individualmente.

Quadro 3 - Alguns aspectos do Planejamento Estratégico, Execução e Controle

1) Qual sua percepção em relação à importância do Planejamento Estratégico na empresa?

2) Se ele não fosse utilizado você acredita que a empresa teria os mesmos resultados?

3) Você acredita que os líderes são agentes de mudanças na execução dos planejamentos da empresa?

4) Como você avalia a coerência entre o planejado e o executado dentro da empresa?

\begin{tabular}{|c|c|}
\hline & $\begin{array}{l}\text { Fundamental para que haja previsão de cenários, determinar os processos, risco de inves } \\
\text { calculados, direcionamento do trabalho, bem como conseguir ter gestão de tudo que foi planej } \\
\text { acompanhar o seu desenvolvimento, para possíveis tomadas de decisões sustentáve } \\
\text { planejamento, se ele não fosse utilizado não teríamos os mesmos resultados, sim os líderes são } \\
\text { de mudança na execução, mas a coerência está relacionada se toda cadeia estiver dedicada, d }\end{array}$ \\
\hline
\end{tabular}




\section{PLANEJAMENTO ESTRATÉGICO DE EMPRESA DO SETOR DE TELECOMUNICAÇÕES: UM ESTUDO DO USO PELOS GESTORES COMO APOIO AO PROCESSO DECISÓRIO}

\begin{tabular}{|c|c|}
\hline 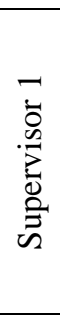 & $\begin{array}{l}\text { Possui total importância, a empresa passou a ter um crescimento mais vigoroso e sustentável, com } \\
\text { maior sustentabilidade e perenidade depois do amadurecimento desse processo, se ele não fosse } \\
\text { utilizado a empresa não teria os mesmos resultados, visto que no passado a empresa tinha diversas } \\
\text { iniciativas com áreas atuando sem convergência e até com sentidos opostos, a empresa gastava recursos } \\
\text { e energia sem sair do lugar, hoje suas iniciativas estão alinhadas com os pilares estratégico, sem essa } \\
\text { coerência não justifica nenhuma execução, os líderes são agentes de mudança, com a metodologia de } \\
\text { acompanhamento das metas, objetivos e pilares estratégicos, e na medida em que o realizado não está } \\
\text { dentro do que foi previsto, nesse momento a tomada de decisão para alterar o rumo é imediata . }\end{array}$ \\
\hline & $\begin{array}{l}\text { Sua importância é devido ao direcionamento do rumo, se não fosse utilizado não teríamos os mesmos } \\
\text { resultados, quando é elaborado o planejamento estratégico é definido para onde iremos e a forma que } \\
\text { chegaremos aos objetivos, na execução do planejamento, os líderes possuem liberdade para levar suas } \\
\text { percepções em relação ao que de fato acontece no mercado e assim sugerir adequação no planejamento, } \\
\text { a avaliação da coerência do planejamento e da execução é complexo devido que nem sempre as } \\
\text { expectativas do mercado correspondem com a realidade, às mutações do mercado são constantes e nem } \\
\text { sempre as sugestões de alterações nos rumos a seguir são aceitas. }\end{array}$ \\
\hline & $\begin{array}{l}\text { O planejamento estratégico é muito importante porque a empresa consegue ter uma visão macro e } \\
\text { micro dos ambientes empresariais, com visão de futuro e análise de riscos, com esses direcionamentos } \\
\text { a empresa possui um êxito maior, com menores falhas, os líderes são agentes de mudanças, e precisa } \\
\text { estar presente auxiliando na execução, mas para que se tenha coerência entre o planejado e executado, é } \\
\text { necessário que as áreas tenham maior sinergia na execução, pois algumas áreas não possuem a } \\
\text { agilidade necessária e algumas vezes há um desvio no que foi planejado pela empresa, devido ao } \\
\text { envolvimento das áreas. }\end{array}$ \\
\hline 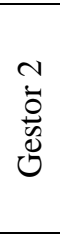 & $\begin{array}{l}\text { Sem dúvidas é necessário que a empresa tenha um planejamento estratégico, sem ele não é possível } \\
\text { permanecer no mercado, é necessário ter foco, objetivo, sem norte não se chega a nenhum lugar, sem } \\
\text { ele não seria possível obter os mesmos resultados, os líderes são agentes de mudanças, às vezes existe } \\
\text { uma distância entre o que é necessário e aquilo que é possível, o líder precisa saber ao tomar decisões } \\
\text { de que forma analisar, para aqueles que estão na linha frente existe um exigência maior, porém nem } \\
\text { tudo é possível de ser executado, sendo necessário manter um equilíbrio na cobrança. }\end{array}$ \\
\hline & $\begin{array}{l}\text { Hoje uma grande empresa precisa ter um planejamento estratégico muito bem elaborado, é necessário } \\
\text { obter conhecimento do mercado no qual atual para garantir que as estratégias serão as melhores em } \\
\text { relação à concorrência, o planejamento é importante junto a execução, sem a sua utilização os } \\
\text { resultados da empresa seriam menores, os líderes possuem uma visão de mercado e captam a visão das } \\
\text { pessoas que estão em sua equipe, baseado nisso, é possível uma adequação no planejamento ideal. }\end{array}$ \\
\hline 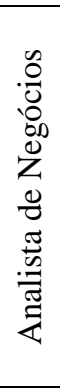 & $\begin{array}{l}\text { Muito importante, não tem como uma grande empresa sobreviver sem um planejamento estratégico, se } \\
\text { ele não existisse a empresa não estaria aonde chegou, ele garante o sucesso dela hoje, antes a empresa } \\
\text { possuía vários projetos, mas sem alinhamento, hoje o número de projetos é menor, porém é mais bem } \\
\text { definido e todos estão alinhados sem perder forças, devido ao alvo ser especifico para atingimento, os } \\
\text { lideres são agentes de mudanças, mas é necessário melhoria na execução, todos estão alinhados com as } \\
\text { estratégias, mas se perdem na execução, os líderes precisam de melhores controles, plano de ações } \\
\text { mais efetivo, maior direcionamento de suas equipes, é notório que alguns se perdem em problemas } \\
\text { operacionais, e outros faltam conhecimento dos projetos planejados, o que trava a execução, é preciso } \\
\text { que o aprimoramento seja a todo o momento e o acompanhamento dos líderes seja mais próximo da } \\
\text { execução. }\end{array}$ \\
\hline
\end{tabular}

Fonte: Dados da pesquisa.

Pode-se observar que todos os entrevistados sabem da importância do Planejamento Estratégico, e defendem em suas respostas, as vantagens no qual a organização possui devido à utilização deste instrumento de gestão. Todos acreditam que os resultados obtidos pela empresa são devidos à metodologia utilizada no planejamento, que possui maior foco nos objetivos definidos pelos seus pilares estratégicos, os quais irão levar a empresa a alcançar o lucro almejado e proporcionar o aumento da participação neste segmento de mercado.

Foi evidenciado que os líderes possuem consciência de serem agentes de mudanças na Execução, visto que o Planejamento Estratégico irá direcioná-los para alcançar os objetivos principais da empresa no longo prazo, e a avaliação dos líderes em relação à coerência do que foi planejado e executado, demonstra que está em consonância com aquilo que é desenhado pela empresa em suas etapas, ou seja, na medida em que a execução acontece, os responsáveis pelos planos aprendem o que precisa ser melhorado ou ser mantido. 


\section{PLANEJAMENTO ESTRATÉGICO DE EMPRESA DO SETOR DE TELECOMUNICAÇÕES: UM ESTUDO DO USO PELOS GESTORES COMO APOIO AO PROCESSO DECISÓRIO}

Existem alguns pontos que podem não garantir a coerência do que foi planejado na hora da execução e para que haja coerência, é necessário engajamento de todos os funcionários e, assim, manter o foco no que foi definido para a empresa como um todo, com clareza na participação de sua área para garantir que os esforços estejam totalmente direcionados a alcançar os pilares estratégicos da organização. O Quadro 4 apresenta os resultados da entrevista acerca da utilização do Planejamento Estratégico pelos líderes.

Quadro 4 - Utilização do Planejamento Estratégico pelos líderes

\begin{tabular}{|c|c|}
\hline $\begin{array}{l}\text { 1) } \\
\text { 2) } \\
\text { 3) } \\
\text { 4) }\end{array}$ & $\begin{array}{l}\text { De que forma o Planejamento Estratégico é utilizado na gestão da empresa? } \\
\text { Quem utiliza o Planejamento Estratégico? } \\
\text { Essas pessoas são avaliadas pela execução e controle do Planejamento Estratégico? } \\
\text { Existe uma área da empresa que cuida do planejamento para garantir sua continuidade? }\end{array}$ \\
\hline 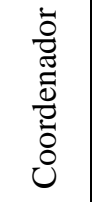 & $\begin{array}{l}\text { A utilização dos principais planejamentos está em linha com o Portfolio Management Office (PMO), } \\
\text { com validação de todas as diretorias e presidência, o planejamento estratégico é utilizado por todas as } \\
\text { diretorias. }\end{array}$ \\
\hline 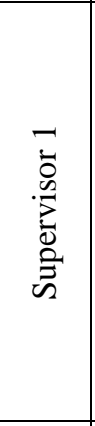 & $\begin{array}{l}\text { É a base do processo de gestão, nenhum investimento, projeto e iniciativa acontecem sem com que o } \\
\text { esforço esteja direcionado com as estratégias da empresa, todos os recursos despendidos devem estar } \\
\text { dentro dos pilares estratégicos, nada se justifica fazer sem a coerência dos pilares, o planejamento } \\
\text { estratégico vem do topo da pirâmide com o direcionamento do negócio como um todo e passa por } \\
\text { todas as áreas até a base para garantir a execução. Essas pessoas são avaliadas pela execução e } \\
\text { controle, esse processo acontece pelos projetos que são criados por executivos, e delegadas ações para } \\
\text { demais responsáveis que juntos formarão uma equipe, e assim garantem a execução do projeto, } \\
\text { mensalmente esse projeto passa pela unidade organizacional do PMO, lá ele ganha uma sinalização por } \\
\text { semáforo, para saber o status da execução, se tornando um processo formal de controle, e posterior a } \\
\text { isso é apresentado para toda organização, existe uma área que garante a continuidade que é uma } \\
\text { assessoria de planejamento estratégico, que está ligada com a presidência. }\end{array}$ \\
\hline 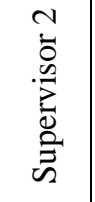 & $\begin{array}{l}\text { A Direção da empresa utiliza o planejamento estratégico para tomar as decisões e rumo a seguir de } \\
\text { cada área/segmento, repassando para os supervisores na execução do plano que é elaborado, os } \\
\text { participantes do planejamento estratégico são avaliados pelas execuções e controle, diariamente são } \\
\text { cobrados pela execução do plano que foi elaborado em salas de reuniões esporádicas, existe a área do } \\
\text { PMO que garante a continuidade do planejamento. }\end{array}$ \\
\hline 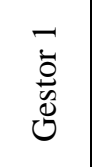 & $\begin{array}{l}\text { É utilizado para direcionar o caminho a seguir e definir o objetivo que será traçado, qual resultado } \\
\text { queremos chegar e de que forma chegaremos nesses objetivos, ele é utilizado por todas as áreas da } \\
\text { empresa, e as pessoas são avaliadas pelo que foi executado em relação ao que foi executado, as áreas } \\
\text { que garantem a continuidade do planejamento são: Supervisão, Gestão e Equipe de vendas. }\end{array}$ \\
\hline 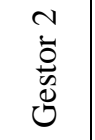 & $\begin{array}{l}\text { Reuniões de decisões e repasses para empresa, quem utiliza o planejamento estratégico são os } \\
\text { Diretores que elaboram o planejamento e repassam para toda empresa, as pessoas são avaliadas pela } \\
\text { execução e controle e existe uma área que acompanha, porém não foi informado o nome da área. }\end{array}$ \\
\hline 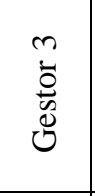 & $\begin{array}{l}\text { De acordo com os objetivos que a empresa deseja alcançar é realizado o planejamento estratégico, ele } \\
\text { é elaborado com base na missão, visão, valores e objetivos da empresa, é realizado pelo marketing e } \\
\text { repassado para todos da empresa utilizarem. Não são avaliadas pela execução e nem pelo controle do } \\
\text { planejamento estratégico, são avaliadas por metas e números, existe uma área de marketing que cuida } \\
\text { do planejamento estratégico. }\end{array}$ \\
\hline 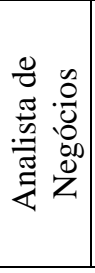 & $\begin{array}{l}\text { O planejamento estratégico da empresa é muito bem divulgado para que todos os líderes utilizem na } \\
\text { gestão, todos os projetos hoje desenvolvidos pela empresa estão interligados com as estratégias da } \\
\text { organização, e todos são avaliados, desde objetivos individuais, no qual os funcionários recebem um } \\
\text { valor extra por ano para garantir a execução de micro atividades, aos projetos maiores desenvolvidos } \\
\text { em equipes, a empresa possui um dashboard onde acompanha todos os resultados das Diretorias, para } \\
\text { garantir a continuidade esses indicadores são acompanhados pela área do PMO, e os orçamentos da } \\
\text { empesa estão voltados para esses projetos. }\end{array}$ \\
\hline
\end{tabular}

Fonte: Dados da pesquisa. 


\section{PLANEJAMENTO ESTRATÉGICO DE EMPRESA DO SETOR DE TELECOMUNICAÇÕES: UM ESTUDO DO USO PELOS GESTORES COMO APOIO AO PROCESSO DECISÓRIO}

Conforme dados dos documentos pesquisados, a empresa possui uma unidade organizacional, no qual têm por objetivo disseminar as boas práticas de gestão de projetos, e realizar análises de desempenho dos programas e projetos que compõem o portfólio da empresa; estas análises possuem foco em negócio e servem de apoio à tomada de decisão do comitê diretivo.

Uma visão integrada de todos os programas e projetos do portfólio são de fundamental importância para que o Portfolio Management Office (PMO) possa estabelecer as correlações com os objetivos estratégicos e respectivos impactos nos resultados gerais das empresas, sendo assim, após a tradução da estratégia e desdobramento das áreas para execução de todos da organização, o controle acontece com a equipe do PMO, segundo as respostas, 4 líderes (57\%) possuem conhecimento dos processos do Planejamento Estratégico e das responsabilidade das áreas, para garantir a continuidade dos processos. O Quadro 5 apresenta os resultados da pesquisa acerca da tomada de decisão dos líderes.

Quadro 5 - Tomada de decisão dos líderes

1) Quais as decisões são tomadas no seu dia-a-dia?

2) O seu cargo permite tomar decisões sozinho ou é necessário autorização de outros níveis hierárquicos?

3) Elas estão em quais níveis: Estratégico, Tático, Operacional ou Imediata?

\begin{tabular}{|c|c|}
\hline 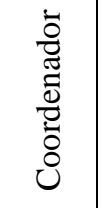 & $\begin{array}{l}\text { As principais são: Setor comercial, mercado, canais de atendimento e vendas, comissão, incentivos e } \\
\text { investimentos, decisões operacionais e táticos praticamente } 100 \% \text {. Quanto a nível estratégico e nível } \\
\text { comercial } 80 \% \text {, quanto a decisões de mercado é necessário dividir com a equipe de marketing e } \\
\text { validação do Diretor, as decisões acontecem em todos os níveis: estratégico, tático, operacional e } \\
\text { imediata. }\end{array}$ \\
\hline 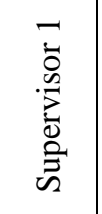 & $\begin{array}{l}\text { Decisões no âmbito da execução, pois as metas são definidas pela Direção, decisões de estrutura } \\
\text { comercial, decisões de contratação de gestores e vendedores, estratégias de vendas, a maioria das } \\
\text { decisões é tomada sozinho, todas as que estão ligadas a operação não dependem de outros níveis } \\
\text { hierárquicos, correspondendo a aproximadamente } 65 \% \text { das decisões, as estratégias são tomadas nos } \\
\text { níveis: tático, operacional e imediata. }\end{array}$ \\
\hline 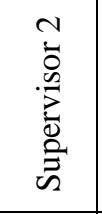 & $\begin{array}{l}\text { As decisões tomadas no dia-a-dia estão ligadas aos liderados, decisões de produtos estratégicos que } \\
\text { devem ser vendidos, como venderem, como os canais de atendimentos irá interagir com o mercado, } \\
\text { decisões de interação entre equipes, a maioria das decisões são tomadas sozinho, cerca de } 70 \% \text { sem } \\
\text { interferência de outros níveis hierárquicos, as decisões são tomadas nos níveis: tático, operacional e } \\
\text { imediata. }\end{array}$ \\
\hline 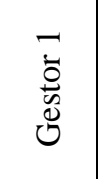 & $\begin{array}{l}\text { Na execução do planejamento, como atuar no mercado, mudanças de rotas quando necessário, } \\
\text { negociação de vendas, fechamento de grandes contratos e direcionamento dos vendedores, a maioria } \\
\text { das decisões são tomadas sozinho, são aproximadamente } 70 \% \text {, os níveis de decisões são: operacional e } \\
\text { imediata. }\end{array}$ \\
\hline 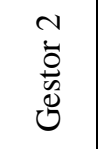 & $\begin{array}{l}\text { Decisões de negociações de vendas, permanência de vendedores na equipe e se necessário novas } \\
\text { contratações, na maioria dos casos a decisão é tomada sozinho, cerca de } 80 \% \text {, e casos específicos são } \\
\text { enviados para outros níveis superiores, as decisões estão nos níveis: operacional e imediata. }\end{array}$ \\
\hline 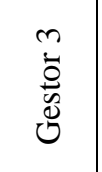 & $\begin{array}{l}\text { Decisões de negociações de vendas, quais produtos deverão ser vendidos, decisões do modelo de } \\
\text { atendimento a serem seguidas pelos vendedores, decisões administrativas, decisões para resolução de } \\
\text { conflitos internos da equipe, e incentivos que serão realizados, a maioria são tomadas sozinho, } \\
\text { aproximadamente } 80 \% \text {, as decisões estão nos níveis: operacional e imediata. }\end{array}$ \\
\hline 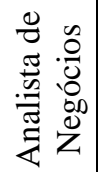 & $\begin{array}{l}\text { Quais investimentos devem ser realizados, quais cidades receberão investimento, priorizações em nível } \\
\text { de importância e impacto nos resultados, utilização de } C A P E X \text {, em alguns momentos é necessária } \\
\text { intervenção de outras pessoas nas decisões, em média } 80 \% \text { das decisões são tomadas sozinho, as } \\
\text { decisões estão em três níveis: tático, operacional e imediata. }\end{array}$ \\
\hline
\end{tabular}

Fonte: Dados da pesquisa. 


\section{PLANEJAMENTO ESTRATÉGICO DE EMPRESA DO SETOR DE TELECOMUNICAÇÕES: UM ESTUDO DO USO PELOS GESTORES COMO APOIO AO PROCESSO DECISÓRIO}

Observou-se no Quadro 5, que as decisões tomadas pelos líderes no cotidiano, seu nível de autonomia para tomar a decisão sem interferência de outros níveis hierárquicos. Em sua maioria, são decisões que irão afetar diretamente nos resultados da empresa, e são realizadas em grande parte sozinha, as decisões no nível estratégico apenas o Coordenador possui autonomia. O Quadro 6 apresenta os critérios utilizados pelos líderes para a tomada de decisão.

Quadro 6 - Critérios utilizados pelos líderes para a tomada de decisão

1) Quais os principais critérios para tomar uma decisão?

2) As decisões tomadas por você são realizadas em consonância com alguma ferramenta de gestão?

\begin{tabular}{|c|c|}
\hline 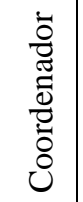 & $\begin{array}{l}\text { Obter dados e fatos, bem como aprender a "correr riscos" que não vão contra os valores da } \\
\text { empresa e ética profissional. }\end{array}$ \\
\hline 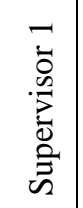 & $\begin{array}{l}\text { Os critérios são: aumento de resultado, diminuição de custos, fidelização de clientes, a ferramenta } \\
\text { utilizada é que a decisão esteja em consonância com os pilares estratégicos da empresa. }\end{array}$ \\
\hline 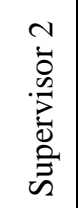 & $\begin{array}{l}\text { Comportamento do mercado e compreensão da demanda, a ferramenta de gestão é baseada nos } \\
\text { objetivos definidos pela organização, toda decisão deve ser baseada para alcançar o objetivo final. }\end{array}$ \\
\hline 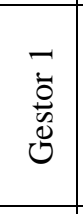 & $\begin{array}{l}\text { Desempenho na entrega dos resultados, comportamento dos vendedores para tomar a decisão da } \\
\text { avaliação individual realizada em seu desenvolvimento profissional, coerência com a missão, visão } \\
\text { e valores da empresa, engajamento na execução, efetividade e forma de aderência no mercado, } \\
\text { grau de competitividade, as ferramentas utilizadas são de acompanhamento dos resultados em } \\
\text { relação ao que foi orçado, e feedback da equipe para identificar pontos a serem melhorados. }\end{array}$ \\
\hline 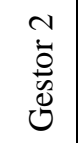 & $\begin{array}{l}\text { Desempenho na entrega dos resultados, embasamento seguro baseado em dados e fatos, a } \\
\text { ferramenta utilizada são informações de demonstrativos de resultado em planilha, baseado em } \\
\text { números. }\end{array}$ \\
\hline 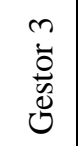 & $\begin{array}{l}\text { Desempenho na entrega dos resultados, é utilizado planilhas de acompanhamento do resultado dos } \\
\text { vendedores. }\end{array}$ \\
\hline 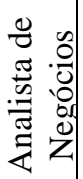 & $\begin{array}{l}\text { Financeiro: disponibilidade e viabilidade, priorização do que precisa ser feito em menor tempo } \\
\text { com maior retorno de investimento, cumprimento das metas, impacto nos clientes, as ferramentas } \\
\text { utilizadas são: análise em matriz } S W O T \text { e } 5 W 2 H \text {, Tempo de retorno nos investimentos. }\end{array}$ \\
\hline
\end{tabular}

Fonte: Dados da pesquisa.

Em síntese, os dados da pesquisa demonstram que os critérios utilizados pelos líderes para tomar decisões estão no envolto de variáveis internas e externas, sendo qualitativas e quantitativas, e o mais citado pelos líderes foi o desempenho na entrega do resultado. Após essa análise, os líderes decidem se é necessária a adaptação ou a continuidade da estratégia utilizada. Sugere-se que os líderes possuem a visão alinhada 


\section{PLANEJAMENTO ESTRATÉGICO DE EMPRESA DO SETOR DE TELECOMUNICAÇÕES: UM ESTUDO DO USO PELOS GESTORES COMO APOIO AO PROCESSO DECISÓRIO}

com as etapas do planejamento, e que, caso seja necessário, nesse momento podem ocorrer a adaptação da estratégia, com possibilidade de criação de estratégias emergentes, visando o objetivo final de lucratividade.

\section{CONSIDERAÇÕES FINAIS}

No tocante aos resultados deste estudo, observa-se que o Planejamento Estratégico possui diversas vantagens, entre elas destacam-se que a empresa pode definir, em seu planejamento, o objetivo final e criar estratégias que serão o caminho para alcançar os resultados esperados.

Nota-se que, em relação ao Planejamento Estratégico, os altos níveis hierárquicos estão mais envolvidos e possuem maior conhecimento; porém, $43 \%$ dos líderes entrevistados não conhecem totalmente as etapas do Planejamento Estratégico e as responsabilidades das áreas, o que dificulta no direcionamento com maior entendimento de seus liderados; os líderes participam da elaboração do Planejamento Operacional, que são criados em consonância com o que é solicitado pela Diretoria, o qual vem de encontro com os pilares estratégicos definidos no planejamento, garantindo assim, um envolvimento nas etapas citadas pela empresa.

A utilização do Planejamento Estratégico pelos líderes e o seu alinhamento com os resultados foi observado pelo estudo, e isso ocorre pois todos da organização possuem objetivos individuais e são responsáveis pela execução no decorrer do ano. Os objetivos individuais contribuem de alguma forma para o atingimento dos objetivos da empresa. Os líderes são remunerados com prêmios extras quando cumpridos com êxito os objetivos, sendo esse um meio de fazer com que todos participem da execução do Planejamento Estratégico.

Identificaram-se também algumas dificuldades na execução do Planejamento Estratégico: (i) seu fluxo pode ser interrompido ou até mesmo não executado devido a decisões tomadas no momento do feedback do controle, para mudar a rota e atingir os resultados; (ii) a sinergia entre as áreas, para que o fluxo do planejamento não pare ou até mesmo demore a ser concluído, minimiza os resultados; (iii) maior envolvimento dos líderes junto a equipe na execução é necessária, para garantir que as estratégias sejam eficazes; (iv) direcionamentos precisam ser mais assertivos, para evitar a perda de esforços e recursos com demandas que não estão em consonância com as diretrizes estratégicas da empresa; (v) envolvimento dos líderes com a base operacional da empresa, para melhorar as estratégias, contribuindo e gerando engajamento dos envolvidos; e (vi) necessidade de sistemas de controle melhores para o Planejamento Operacional, visto que a equipe PMO não controla esses planejamentos e não possui um processo formal de status para controle nos planos de ação ou operacionais elaborados pelos líderes.

Quanto aos critérios utilizados pelos líderes no processo decisório, pode-se destacar que envolvem variáveis internas e externas, qualitativas e quantitativas, com ênfase no desempenho na entrega do resultado, e que, após realizada a análise dos resultados, os líderes decidem se é necessária adaptação ou continuidade da estratégia adotada, para a continuidade dos negócios e o atingimento dos objetivos.

Como este estudo apresenta resultados obtidos de uma única empresa, não é recomendada a generalização dos resultados para outras empresas, mesmo que atuem no mesmo segmento, o que pode ser apontada como uma limitação deste estudo. Sugere-se para estudos futuros a sua realização nas demais empresas do setor, o que pode tornar possível a comparação dos resultados. 


\section{REFERÊNCIAS}

ANATEL. Missão, atribuições e características. Disponível em: http://www.anatel.gov.br/. Acesso em: 27 jun. 2015.

BATAGLIA, W.; YU, A. S. O. A sincronização da tomada de decisão estratégica com o planejamento estratégico formal. Revista de Administração Mackenzie, v. 9, n. 5, p. 82-111, 2008.

CAVAlCANTI, F. A. Planejamento estratégico participativo: concepção, implementação e controle de estratégias. São Paulo: Editora Senac São Paulo, 2008.

CHIAVENATO, I. Administração: teoria, processo e prática. Rio de Janeiro: Elsevier, 2007.

CHIAVENATO, I.; SAPIRO, A. Planejamento estratégico. Rio de Janeiro: Elsevier, 2003.

CHIAVENATO, I; SAPIRO, A. Planejamento estratégico: fundamentos e aplicações da intenção aos resultados. Rio de Janeiro: Elsevier, 2009.

CHIAVENATO, I. Introdução à teoria geral da administração: uma visão abrangente da moderna administração das organizações: compacta. Rio de Janeiro: Elsevier, 2004.

DRUCKER, P. F. Introdução à administração. São Paulo: Pioneira, 1984.

DUARTE, F. P.; AZEREDO, A. J. Orçamento empresarial por projetos alinhado ao plano estratégico de uma empresa prestadora de serviços. Revista Destaques Acadêmicos, v. 5, n. 1, 2013.

FERREIRA, F, B.; DIEHL, C, A. Orçamento empresarial e suas relações com o planejamento estratégico. Pensar Contábil. v. 14, n. 54, p. 46-57, 2012.

FIGUEIREDO, S.; CAGGIANO, P. C. Controladoria: teoria e prática. São Paulo: Atlas, 2004.

GIL, A. C. Métodos e técnicas de pesquisa social. São Paulo: Atlas, 1999.

HITT, M. A.; IRELAND, R. D.; HOSKISSON, R. E. Administração estratégica: competitividade e globalização. São Paulo: Cengage Learning, 2008.

HOJI, M.; SILVA, H. A. Planejamento e controle financeiro: fundamentos e casos práticos de orçamento empresarial. São Paulo: Atlas, 2010.

KAPLAN, R. S.; NORTON, D. P. A estratégia em ação: balanced scorecard. Rio de Janeiro: Campus, 1997.

MANKINS, M. C.; STEELE, R. Stop making plans; start making decisions. Harvard Business Review, v. 2, n. 3056, 2006. 
OLIVEIRA, C. E. Orçamento empresarial passo a passo. São Paulo: edição do autor, 2020.

OLIVEIRA, C. E.; CATANEO, A. A contribuição dos componentes de mensuração quantitativa no planejamento empresarial. In: XVI Simpósio de Engenharia de Produção - SIMPEP. Anais... Bauru, SP, Brasil, 2009.

OLIVEIRA, D. P. R. Planejamento estratégico: conceitos, metodologia e práticas. São Paulo: Atlas, 2013.

PADOVEZE, C. L. Planejamento orçamentário. São Paulo: Cengage Learning, 2010.

PADOVEZE, C. L.; TARANTO, F. C. Orçamento empresarial: novos conceitos e técnicas. São Paulo: Pearson, 2009.

PEREIRA, M. F. Planejamento estratégico: teorias, modelos e processos. São Paula: Atlas, 2010.

RIBEIRO, R.; GARCIA, M. M.; CASAS, A. L. L. Estratégia e vantagem competitiva no mercado brasileiro de telecomunicações: um estudo de casos múltiplos para o período de 1999 a 2007. Revista de Gestão, v. 17, n. 3, p. 297-312, 2010.

SEVERINO, A. J. Metodologia do trabalho científico. São Paulo: Cortez, 2007.

SILVA, J. A. T.; SANTOS, R.F.; SANTOS, N. M. B. F. Criando valor com serviços compartilhados: balanced scorecard. São Paulo: Saraiva, 2006.

TELEBRASIL. O Desempenho do setor de telecomunicações: séries temporais. Disponível em: http://www.telebrasil.org.br/. Acesso em: 13 out. 2015. 